\title{
BASE64 SEBAGAI KUNCI KEAMANAN PADA ONE TIME PAD (OTP)
}

\author{
Oris Krianto Sulaiman*, Khairuddin Nasution, Satria Yudha Prayogi \\ Universitas Islam Sumatera Utara \\ Jl. Sisingamangaraja No.Kelurahan, Teladan Barat, Kec. Medan Kota, Kota Medan, Sumatera Utara 20217 \\ *oris.ks@ft.uisu.ac.id
}

\begin{abstract}
Abstrak - Keamanan pesan dalam komunikasi menjadi hal yang sangat penting untuk menjaga kerahasiaan dan keutuhan pesan. Pesan yang dikirimkan harus tersampaikan secara utuh dan hanya tersampaikan sesuai dengan tujuan. One Time Pad atau OTP merupakan sebuah algoritma yang dapat melakukan enkripsi pesan menjadi ciphertext sehingga keamanan pesan dapat terjamin. OTP merupakan algoritma kriptografi simetri, yaitu kunci untuk enkripsi dan dekripsi adalah kunci yang sama. Untuk melakukan enkripsi maka panjang plaintext OTP harus sama dengan panjang kunci. Hal ini akan menyulitkan ketika terdapat panjang plaintext yang sangat panjang sehingga kunci juga harus menyesuaikan hal tersebut. Kunci OTP juga terdapat kelemahan jika sebuah kunci sudah digunakan lebih dari sekali. Oleh sebab itu dibutuhkan pembangkin kunci. Pada penelitian ini pembangkit kunci yang digunakan adalah base64. Base64 digunakan untuk merubah bit dari plaintext yang akan digunakan oleh OTP. Pada penelitian ini base64 dapat encode plaintext untuk kemudian digunakan sebagai kunci OTP sehingga berhasil menjadikan pembangkit kunci dari encode base 64.
\end{abstract}

Kata Kunci-Base64, One Time Pad, Kunci Keamanan, Keamanan Pesan.

Abstract-Message security in communication is very important to maintain the confidentiality and integrity of messages. The message that is sent must be conveyed in its entirety and only delivered according to its purpose. One Time Pad or OTP is an algorithm that can encrypt messages into ciphertext so that message security can be guaranteed. OTP is a symmetric cryptographic algorithm, that is, the key for encryption and decryption is the same. To perform encryption, the OTP plaintext length must be the same as the key length. This will make it difficult when there is a very long length of plaintext, so the key must also adjust it. OTP keys also have a weakness if a key has been used more than once. Therefore a key builder is needed. In this research, the key generator used is base64. Base64 is used to change the bits of plaintext that will be used by OTP. In this study, base64 can encode plaintext to be used as an OTP key so that it succeeded in making the key generator from base 64 encoding.

Keywords-Base64, One Time Pad, Security Key, Message Security.

\section{PENDAHULUAN}

Dalam berkomunikasi sangat penting menjaga kerahasiaan dan keutuhan dari pesan yang disampaikan. Banyak algoritma yang dapat menjadikan pesan tersebut menjadi teks acak atau sandi yang dikenal juga dengan sebutan ciphertext. Salah satu algoritma tersebut adalah One Time Pad atau OTP. Dalam proses enkripsi, algoritma OTP mengharuskan jumlah karakter teks asli atau plaintext sama dengan jumlah karakter kunci [1], [2].

Ada banyak teknik yang dapat digunakan dalam membuat kunci otomatis untuk OTP agar keamanan dan efisiensi pembuatan kunci jadi lebih baik. Base64 merupakan sebuah algoritma yang merubah biner dari 8 bit menjadi 6 bit untuk setiap karakternya [3]. Pada penelitian terdahulu Rahim dkk. [4] dalam artikelnya yang berjudul "Combination Base64 Algorithm and EOF Technique for Steganography" membahas permasalahan keamanan pada steganography dan meningkatkan keamanan menggunakan steganography dengan kombinasi algoritma Empirical Orthogonal Functions (EOF), pada penelitian ini menghasilkan proses EOF dari encoding base64. Minarni [3] dalam artikelnya yang berjudul "Implementasi Algoritma Base64 untuk Mengamakan SMS pada Smartphone" membahas peningkatan keamanan SMS dan menghasilkan keamanan text SMS dengan encode base64. Rahim dkk. [5] pada artinya yang berjudul "Base64, End of File and One Time Pad for Improvement Steganography Securit" membahas peningkatan teknik steganography dengan menggunakan base64 dan OTP, pada penelitian ini kunci yang digunakan dibuat tersendiri. Pada penelitian ini base64 akan digunakan sebagai kunci yang ada pada OTP untuk memberikan kunci otomatis dan meningkatkan kunci keamanan pada OTP pada saat enkripsi pesan.

\section{A. One Time Pad (OTP)}

OTP merupakan algoritma kriptografi yang dapat mengenkripsi pesa dengan sangat baik. OTP 
menggunakan kunci simetri, dimana kunci enkripsi dan dekripsi pesan menggunakan kunci yang sama. Panjang kunci dari OTP harus sama dengan panjang pesan yang akan di enkripsi atau dekripsi [1], [3], [6][8]. OTP menggunakan formula

$$
\begin{aligned}
& c=(p+k) \bmod n \\
& p=(c-k) \bmod n
\end{aligned}
$$

jika plaintext oris dan kunci srie maka setelah di enkripsi menggunakan OTP akan menjadi giqw. Dalam hal ini OTP juga berpengaruh pada $n$ yaitu berapa banyak jumlah karakter yang digunakan pada algoritma OTP.

\section{B. Base64}

Merupakan algoritma encode dan decode bit pada teks [3], [4], [9], [10]. Tiap-tiap karakter yang ada pada teks terdiri dari 8 bit dalam bilangan binner yang sesuai dengan ASCII. Pada base64 akan digabung bitbit tersebut dan disusun menjadi 6 bit dari tabel base64. Sehingga menhasilkan krakter yang berbeda dari teks sebelumnya.

Plaintext: oris

Encode base64: b3Jpcw==

\section{METODE PENELITIAN}

Metode yang digunakan pada penelitian ini menggunakan algoritma One Time Pad (OTP) dan Base 64. Plaintext atau teks asli akan di enkripsi menggunakan algoritma One Time Pad (OTP) dengan kunci yang panjangnya sesuai dengan teks yang akan di enkripsi.

$$
\begin{aligned}
& c=(p+k) \bmod n \\
& p=(c-k) \bmod n
\end{aligned}
$$

dimana:

$p=$ plaintext

$c=$ ciphertext

$k=k e y$

$n=$ number of letters used

Pada penelitian ini akan digunakan karakter yang berjumlah 26 yang diambil dari tabel ASCII. Tabel I memperlihatkan karakter yang digunakan pada penelitian ini berjumlah 26 karakter, sehingga modulo yang digunakan untuk enkripsi dari OTP adalah modulo 26.

TABEL I

ASCII TABLE

\begin{tabular}{|c|c|c|c|c|c|}
\hline Idx & Binary & Char & Idx & Binary & Char \\
\hline 0 & 01100001 & $\mathrm{a}$ & 13 & 01101110 & $\mathrm{n}$ \\
\hline 1 & 01100010 & $\mathrm{~b}$ & 14 & 01101111 & $\mathrm{o}$ \\
\hline 2 & 01100011 & $\mathrm{c}$ & 15 & 01110000 & $\mathrm{p}$ \\
\hline 3 & 01100100 & $\mathrm{~d}$ & 16 & 01110001 & $\mathrm{q}$ \\
\hline 4 & 01100101 & $\mathrm{e}$ & 17 & 01110010 & $\mathrm{r}$ \\
\hline 5 & 01100110 & $\mathrm{f}$ & 18 & 01110011 & $\mathrm{~s}$ \\
\hline 6 & 01100111 & $\mathrm{~g}$ & 19 & 01110100 & $\mathrm{t}$ \\
\hline 7 & 01101000 & $\mathrm{~h}$ & 20 & 01110101 & $\mathrm{u}$ \\
\hline 8 & 01101001 & $\mathrm{i}$ & 21 & 01110110 & $\mathrm{v}$ \\
\hline
\end{tabular}

\begin{tabular}{|c|c|c|c|c|c|}
\hline 9 & 01101010 & j & 22 & 01110111 & w \\
\hline 10 & 01101011 & $\mathrm{k}$ & 23 & 01111000 & $\mathrm{x}$ \\
\hline 11 & 01101100 & $\mathrm{l}$ & 24 & 01111001 & $\mathrm{y}$ \\
\hline 12 & 01101101 & $\mathrm{~m}$ & 25 & 01111010 & $\mathrm{z}$ \\
\hline
\end{tabular}

Kunci OTP yang ditentukan akan di encode oleh base64 dan akan di decode kembali ketika proses dekripsi akan dilakukan. Tabel II memperlihatkan indeks base64.

TABEL II

BASE64 INDEX

\begin{tabular}{|c|c|c|c|c|c|}
\hline Index & Binary & Char & Index & Binary & Char \\
\hline 0 & 000000 & A & 33 & 100001 & h \\
\hline 1 & 000001 & B & 34 & 100010 & i \\
\hline 2 & 000010 & C & 35 & 100011 & j \\
\hline 3 & 000011 & D & 36 & 100100 & k \\
\hline 4 & 000100 & E & 37 & 100101 & l \\
\hline 5 & 000101 & F & 38 & 100110 & m \\
\hline 6 & 000110 & G & 39 & 100111 & n \\
\hline 7 & 000111 & H & 40 & 101000 & o \\
\hline 8 & 001000 & I & 41 & 101001 & p \\
\hline 9 & 001001 & J & 42 & 101010 & q \\
\hline 10 & 001010 & K & 43 & 101011 & r \\
\hline 11 & 001011 & L & 44 & 101100 & s \\
\hline 12 & 001100 & M & 45 & 101101 & t \\
\hline 13 & 001101 & N & 46 & 101110 & u \\
\hline 14 & 001110 & O & 47 & 101111 & V \\
\hline 15 & 001111 & P & 48 & 110000 & w \\
\hline 16 & 010000 & Q & 49 & 110001 & x \\
\hline 17 & 010001 & R & 50 & 110010 & y \\
\hline 18 & 010010 & S & 51 & 110011 & Z \\
\hline 19 & 010011 & T & 52 & 110100 & 0 \\
\hline 20 & 010100 & U & 53 & 110101 & 1 \\
\hline 21 & 010101 & V & 54 & 110110 & 2 \\
\hline 22 & 010110 & W & 55 & 110111 & 3 \\
\hline 23 & 010111 & X & 56 & 111000 & 4 \\
\hline 24 & 011000 & Y & 57 & 111001 & 5 \\
\hline 25 & 011001 & Z & 58 & 111010 & 6 \\
\hline 26 & 011010 & a & 59 & 111011 & 7 \\
\hline 27 & 011011 & b & 60 & 111100 & 8 \\
\hline 28 & 011100 & c & 61 & 111101 & 9 \\
\hline 29 & 011101 & d & 62 & 111110 & + \\
\hline 30 & 011110 & e & 63 & 111111 & / \\
\hline 31 & 011111 & f & \multirow{2}{*}{ Padding } & \multirow{2}{*}{ = } \\
\hline 32 & 100000 & g & & & \\
\hline & & & & & \\
\hline
\end{tabular}

Berikut flowchart enkripsi dan dekripsi algoritma OTP dan Base 64 untuk keamanan kunci dari OTP. 


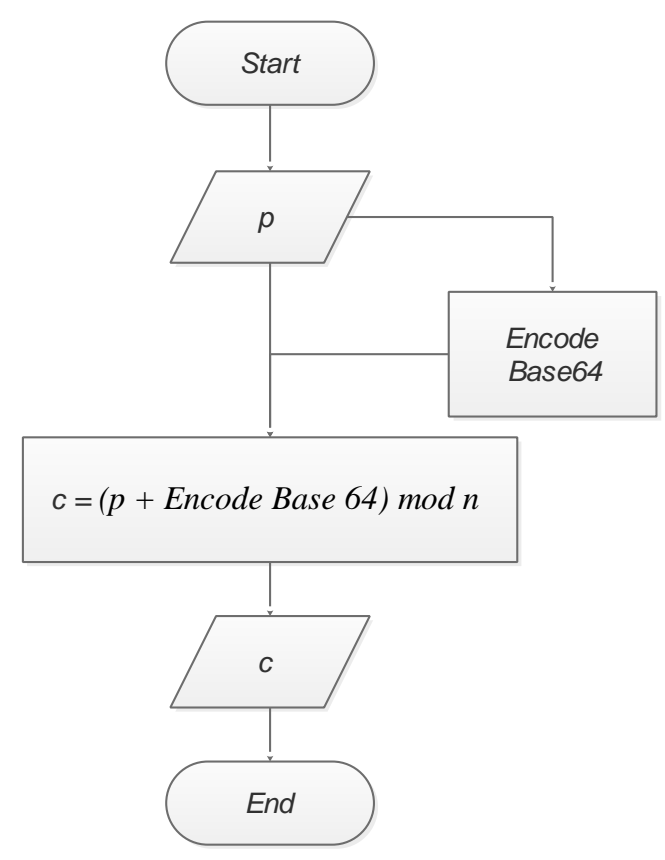

Gbr. 1 Proses enkripsi

Pada gambar terlihat bahwa kunci yang digunakan untuk melakukan enkripsi oleh algoritma OTP berasal dari encode menggunakan base64. Setelah mendapatkan encode base64 maka OTP akan diproses sehingga menghasilkan ciphertext.

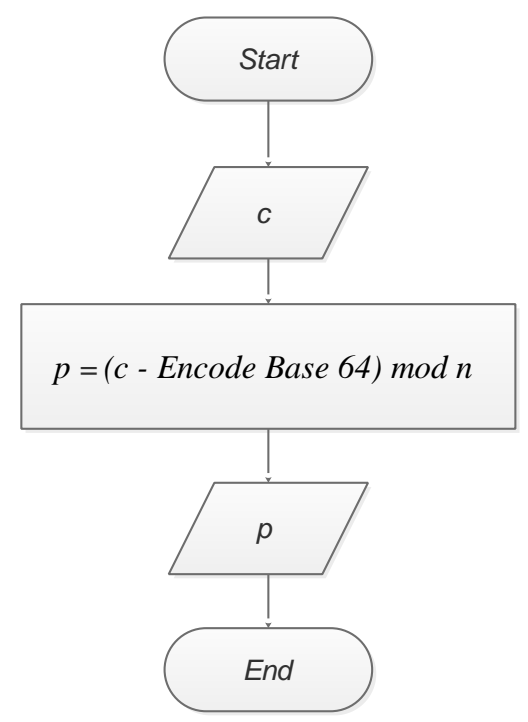

Gbr. 1 Proses dekrips

Untuk proses dekripsi maka ciphertext akan di proses dengan OTP dengan kunci yang sama yaitu encode base 64 dari plaintext. Sehingga akan menghasilkan plaintext.

\section{HASIL DAN PEMBAHASAN}

Percobaan yang dilakukan adalah dengan menggunakan plaintext "srie djoewita lisady" dan kunci akan dihasilkan dari plaintext tersebut berdasarkan proses yang dilakukan oleh base64.

Plaintext: srie djoewita lisady

Base64: c3JpZSBkam9ld210YSBsaXNhZHk= Jumlah karakter encode base64 disesuaikan dengan jumlah karakter yang ada pada plaintext. Karakter plaintext berjumlah 18 karakter maka encode base64 yang diambil adalah 18 karakter juga. Sehingga menghasilkan plaintext dan encode base64 berikut:

Plaintext: srie djoewita lisady

Base64: c3Jp ZSBkam91 d210YS

TABEL III

PROSES ENKRIPSI OTP DENGAN BASE64

\begin{tabular}{|c|c|c|}
\hline Plaintext & Base64 & Ciphertext \\
\hline s & c & u \\
\hline r & 3 & a \\
\hline i & J & x \\
\hline e & p & d \\
\hline d & Z & v \\
\hline j & S & k \\
\hline o & B & y \\
\hline e & k & e \\
\hline w & a & i \\
\hline i & m & t \\
\hline t & 9 & w \\
\hline a & l & l \\
\hline l & d & j \\
\hline i & 2 & a \\
\hline s & l & s \\
\hline a & 0 & a \\
\hline d & Y & d \\
\hline y & S & y \\
\hline
\end{tabular}

Dari proses perhitungan OTP dengan kunci yang dihasilkan dari base64 maka didapatkan hasil dari ciphertext: uaxd vkyeitwl jasady. Untuk dekripsi maka digunakan kunci yang sama dari base64 kemudian dilakukan proses OTP sehingga menghasilkan Kembali plaintext: srie djoewita lisady

TABEL IV PROSES DEKRIPSI OTP DENGAN BASE64

\begin{tabular}{|c|c|c|}
\hline Ciphertext & Base64 & Plaintext \\
\hline u & c & s \\
\hline a & 3 & r \\
\hline x & J & i \\
\hline d & p & e \\
\hline v & Z & d \\
\hline k & S & j \\
\hline y & B & o \\
\hline e & k & e \\
\hline i & a & w \\
\hline t & $\mathrm{m}$ & i \\
\hline w & 9 & t \\
\hline l & l & l \\
\hline j & d & \\
\hline
\end{tabular}




\begin{tabular}{|c|c|c|}
\hline $\mathrm{a}$ & 2 & $\mathrm{i}$ \\
\hline $\mathrm{s}$ & $\mathrm{l}$ & $\mathrm{s}$ \\
\hline $\mathrm{a}$ & 0 & $\mathrm{a}$ \\
\hline $\mathrm{d}$ & $\mathrm{Y}$ & $\mathrm{d}$ \\
\hline $\mathrm{y}$ & $\mathrm{S}$ & $\mathrm{y}$ \\
\hline
\end{tabular}

Dalam percobaan tersebut 18 karakter dari plaintext mendapatkan kunci yang dihasilkan dari encode base64 plaintext. Hal ini membantu dalam pembentukan kunci keamanan untuk One Time Pad (OTP), karena OTP membutuhkan kunci yang panjangnya sama dengan panjang dari karakter plaintext. Setelah mendapatkan kunci maka operasi OTP dapat dilakukan.

\section{IV.PENUTUP}

Penelitian menggunakan base64 sebagai pembangkin bilangan untuk kunci pada One Time Pad (OTP) telah berhasil dilakukan. Hasil yang diperoleh menunjukkan bahwa kunci secara otomatis akan membentuk base64 dan tidak memerlukan pembuatan kunci secara manual. Panjang kunci yang dihasilkan dari encode plaintext base64 lebih banyak daripada panjang kunci plaintext, hal ini disebabkan karena bit yang digunakan per-karakter sebanyak 6 bit. Dalam proses OTP jumlah karakter kunci encode base64 disesuaikan dengan jumlah karakter plaintext yang akan di enkripsi. Kunci OTP yang dibangkitkan dengan pembangkit bilangan acak akan lebih meningkatkan keamanan pesan, namun kelemahan model ini terletak pada base64, sehingga perlu adanya modifikasi base64 agar pembangkit bilangan sulit untuk di ketahui kriptanalis.

\section{REFERENSI}

[1] J. Clawdia, N. Khairina, and M. K. Harahap, "Implementasi Algoritma Kriptografi One Time Pad (Otp) Dengan Dynamic Key Linear Congruential Generator (Lcg)," Konferensi Nasional Teknologi Informasi dan Komputer (KOMIK), vol. I, pp. 12-14, 2017.

[2] N. Khairina and M. K. Harahap, "Analisis Algoritma One Time Pad Dengan Algoritma Cipher Transposisi Sebagai Pengamanan Pesan Teks," SinkrOn, vol. 1, no. 2, p. 58 , Jun. 2017, doi: 10.33395/sinkron.v1i2.42.

[3] R. Minarni, "Implementasi Algoritma Base64 untuk Mengamakan SMS $\mathrm{p}$ ada Smartphone," Building Informatics, Technology and Science (BITS), vol. 1, no. 1, pp. 28-33, 2019.

[4] R. Rahim et al., "Combination Base64 Algorithm and EOF Technique for Steganography," Journal of Physics: Conference Series, vol. 1007, no. 1, 2018, doi: 10.1088/1742-6596/1007/1/012003.

[5] R. Rahim, R. Ratnadewi, D. Prayama, E. Asri, and D. Satria, "Base64, End of File and One Time Pad for Improvement Steganography Security," IOP Conference Series: Materials Science and Engineering, vol. 407, no. 1, 2018, doi: 10.1088/1757-899X/407/1/012161.

[6] R. Aulia, A. Zakir, and M. Zulhafiz, "Penerapan Algoritma One Time Pad \&amp; Linear Congruential Generator Untuk Keamanan Pesan Teks," InfoTekJar (Jurnal Nasional Informatika dan Teknologi Jaringan), vol. 4, no. 1, pp. 37-41, Sep. 2019, doi: 10.30743/infotekjar.v4i1.1590.

L. E. Pratiwi, R. Marwati, and I. Yusnitha, "Program Aplikasi Kriptografi Penyandian One Time Pad Menggunakan Sandi Vigenere," Jurnal EurekaMatika, vol. 2, no. 1, pp. 43-53, 2014.

S. M. Hardi, D. Hamonangan, and M. Zarlis, "IMPLEMENTASI KRIPTOGRAFI HIBRID DENGAN ALGORITMA ELGAMAL DAN ALGORITMA ONETIME PAD(OTP) DALAM PENGAMANAN FILE AUDIO BERBASIS DESKTOP," TECHSI - Jurnal Teknik Informatika, vol. 10, no. 2, p. 129, Oct. 2018, doi: 10.29103/techsi.v10i2.903.

[9] E. Gunadhi and A. P. Nugraha, "Penerapan Kriptografi Base64 Untuk Keamanan URL (Uniform Resource Locator) Website Dari Serangan SQL Injection," Jurnal Algoritma, vol. 13, no. 2, pp. 391-398, 2017, doi: 10.33364/algoritma/v.13-2.391.

[10] S. Siswanto, M. Anif, and W. Gata, "Penerapan Algoritma Kriptografi TEA Dan Base64 Untuk Mengamankan Email Data Policy Asuransi," Jurnal ELTIKOM, vol. 2, no. 1, pp. 34-41, 2018, doi: 10.31961/eltikom.v2i1.44. 